\title{
An Investigation Into the Prevalence of Behavioral and Environmental Determinants of Cataract
}

\author{
M Kashif, M. Sulaiman, N. Amir, R. Yousaf, Z. Bibi \\ Sir Asim Bukhari
}

asimbukharipk@gmail.com

\section{Undergraduate Students Medical, Biomedical and Health Science}

What is the measurable prevalence of the variables correlated to the increase in susceptibility to cataract in 3 populations (Qatar, USA and Pakistan)? Is there a link between the lifestyle maintained at youth and the likelihood of contracting cataract at a later stage in life?

\section{Introduction}

- Accounting for $51 \%[1]$ of legal blindness in the world and $18 \%$ in Qatar ${ }^{[2]}$, cataract remains the most prevalent visual impairment.

- Cataract involves the clouding of the eye's lens, which reduces the light that reaches the retina and ultimately minimizes visibility.

- As the world's population ages, cataract will remain a serious healthcare and socioeconomic burden.

- Preventing cataract formation earlier on is the key to alleviating blindness levels in Qatar.

- A study shows that current smoking, body mass index, occupational exposure to light, family history, deficiency of vitamins C, diabetes, myopia, increased the risk of developing a cataract. ${ }^{[3]}$ Another study identifies hypertension, duration of calcium channel blockers use and previous eye surgeries as significant risk factors of cataracts. ${ }^{[4]}$ Occurrence of dehydration was concluded as an important determinant of cataracts in an article. [5]

\section{Methodology}

Qatar (Doha):

658 surveys conducted (55\% Female, $45 \%$ Male)

\section{Pakistan (Multan):}

210 surveys conducted (55\% Male, $45 \%$ Female)

\section{USA (Sacramento):}

300 surveys conducted (63\% Male, $37 \%$ Female)

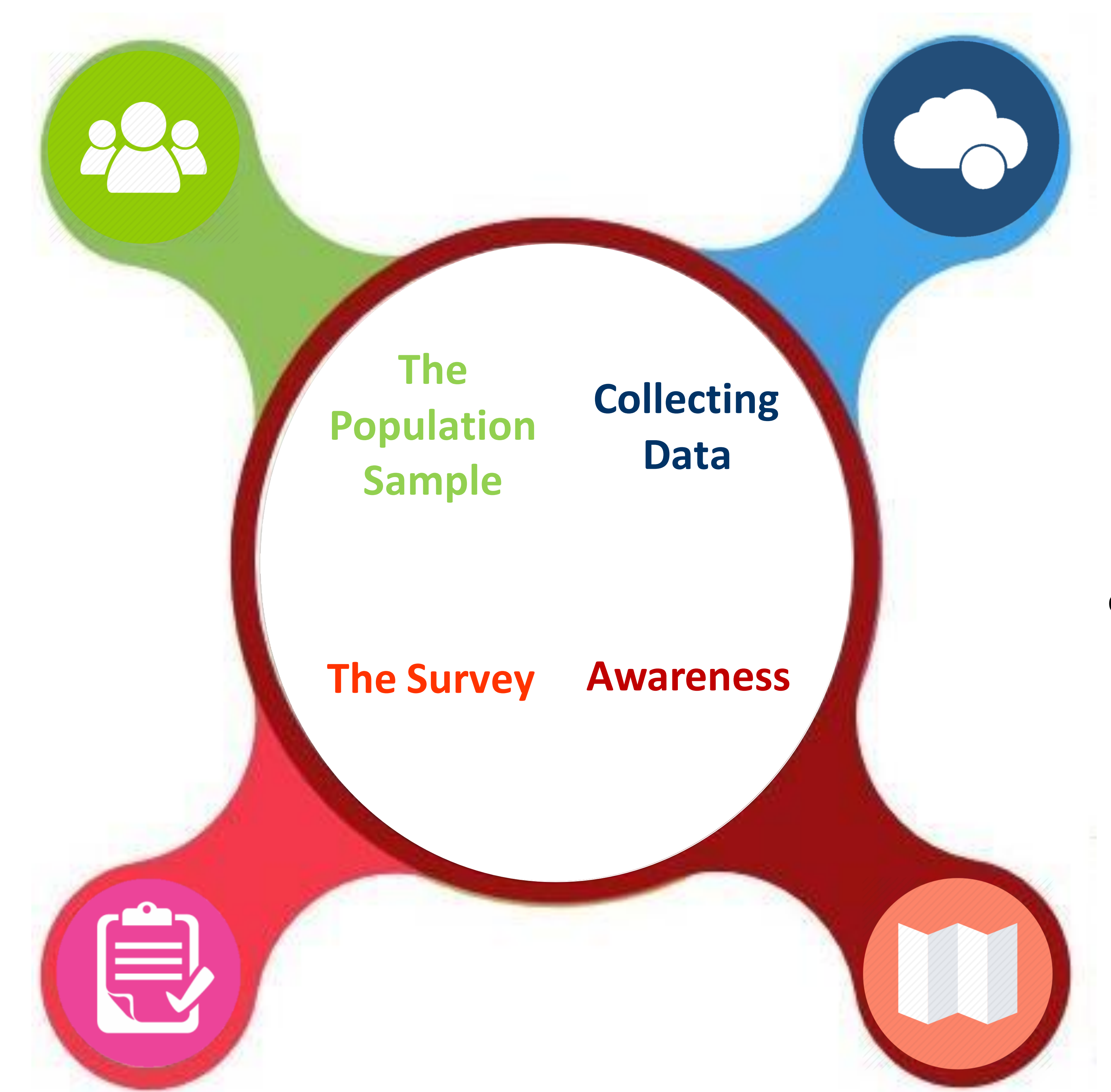

The survey consisted of a series of openended and close-ended questions concerning the participant's daily activities and pre-existing conditions.

Data on relevant demographic and socioeconomic characteristics were collected. Differences in the prevalence of determinants between each demographic were evaluated.

Cataract awareness was raised amongst the youth. Brochures were distributed and a speech on the dangers of cataract and its prevention was given in our school's morning assembly.

Qata

USA

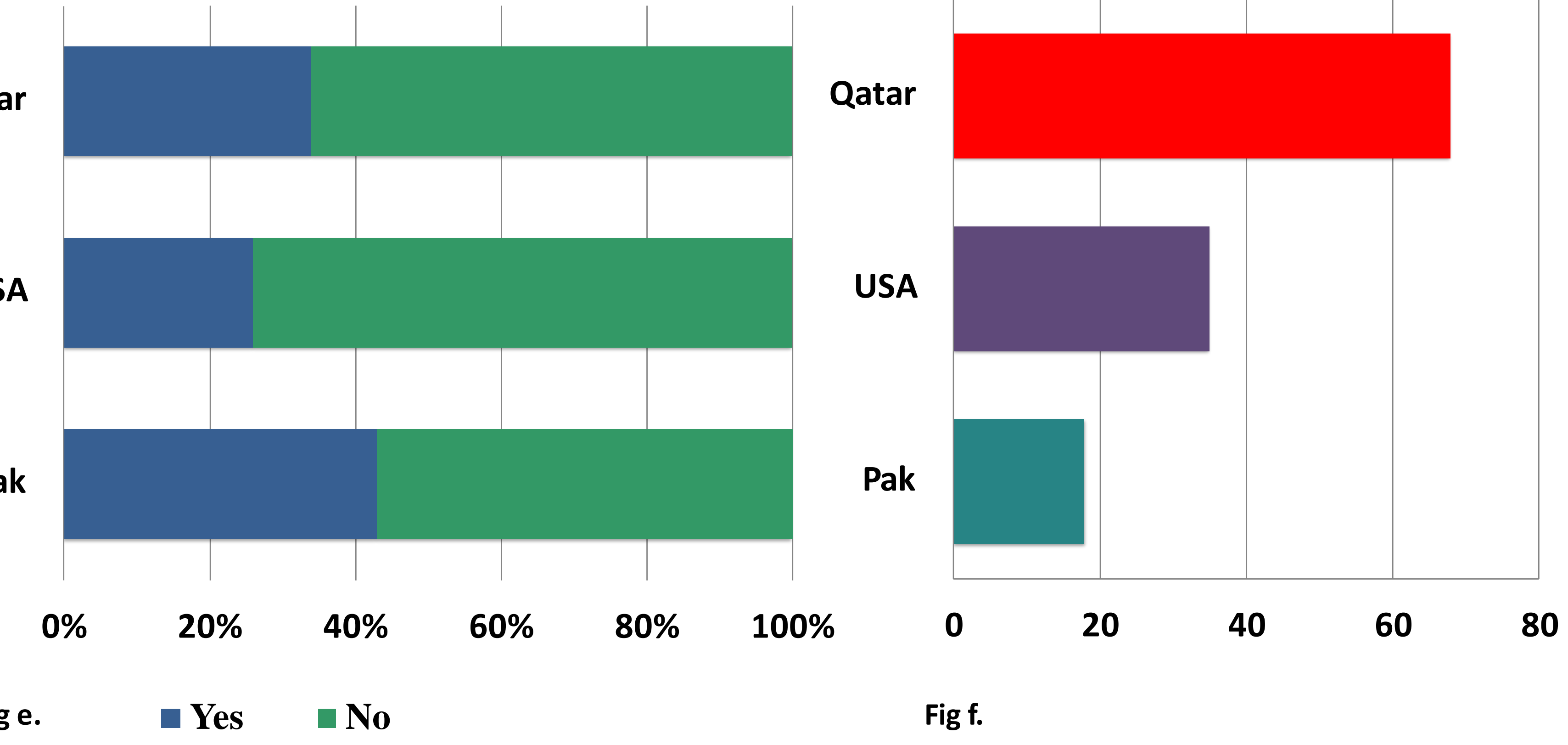

Pak

4 in 10 South Asian individuals in Qatar reported havin myopia. This figure ranks the highest among all ethnicities surveyed.

- Respondents in Qatar afflicted with hypertension represent $27 \%$ of the sample.

- $10 \%$ of participants in Qatar have undergone at least one eye surgery in the past. The most common type of eye procedure among the cohort was laser eye surgery.

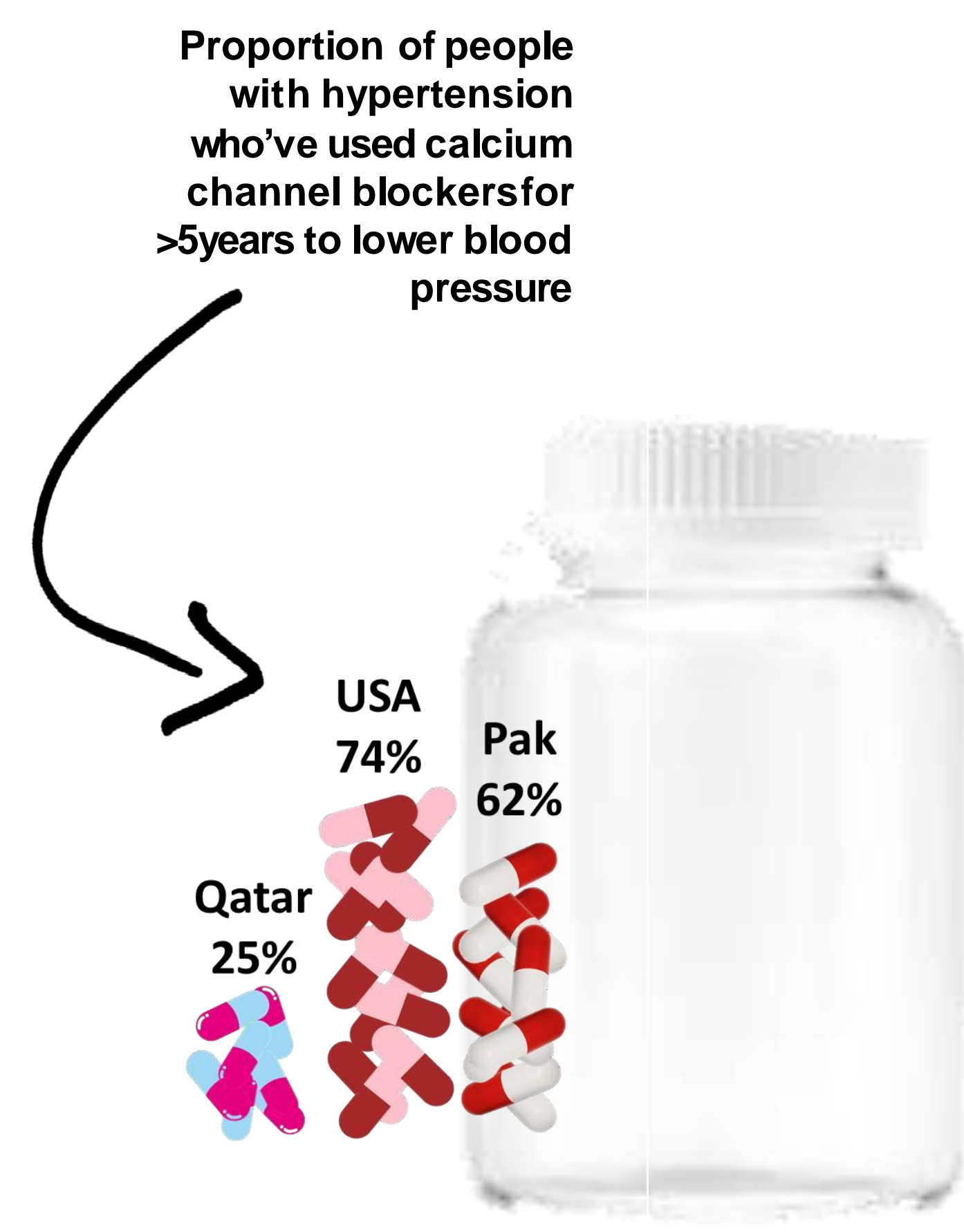

Fig $b$.

- 1 in 3 people in Qatar said that they drink the daily required liters of water. Women are twice more likely than men to stay hydrated.

- $21 \%$ of the residents in Qatar have diabetes or are pre-diabetic.

- Current smokers account for $34 \%$ of the population sample in Qatar. $97 \%$ of this cohort consists of male smokers.

- Other findings of our study are shown in figures $a-f$.

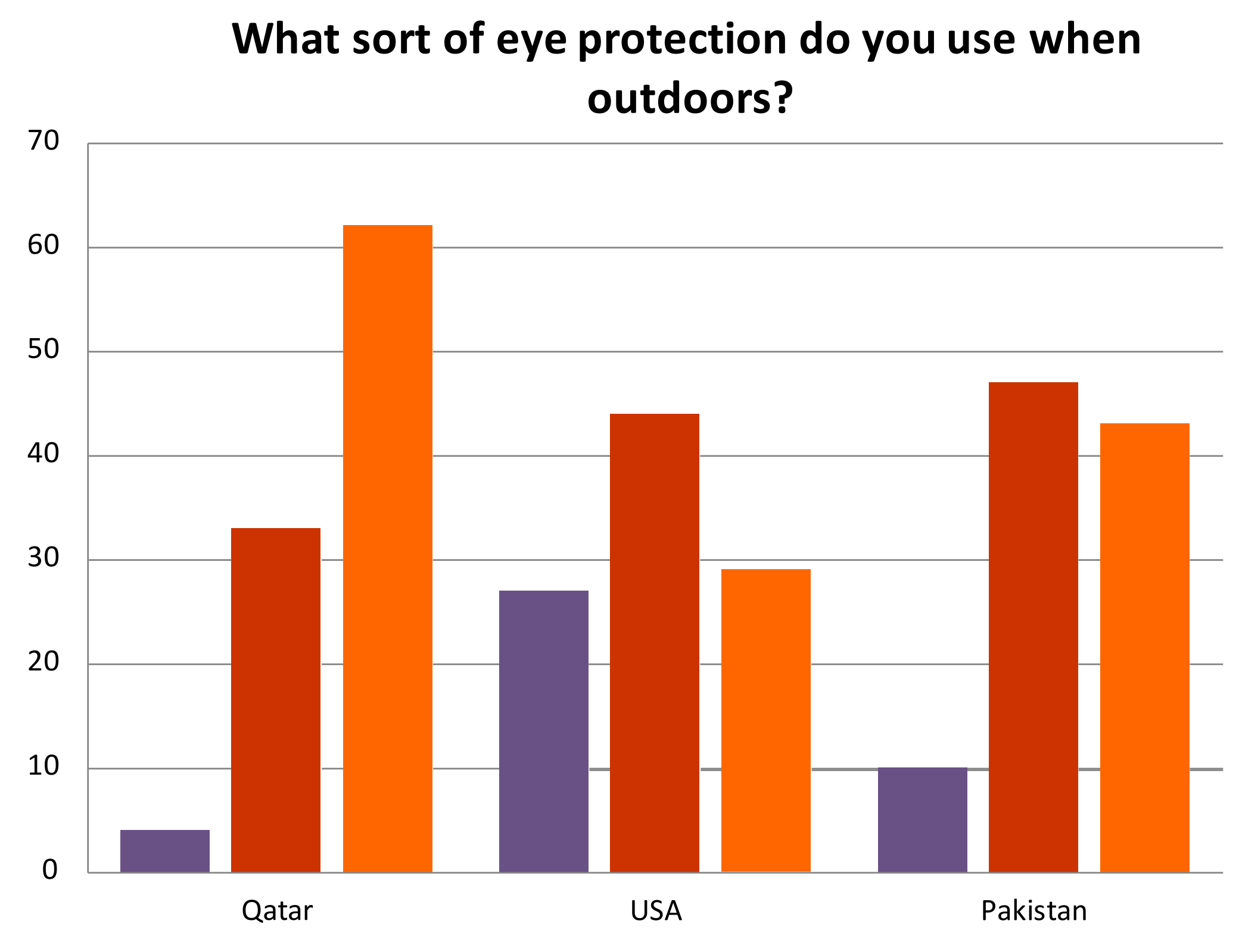
ig c.

- Hat and Sunglasses $\square$ Hat or Sunglasses $\square$ None

Do you have a relative with a cataract?

How many hours in a day do you spend outside? (Qatar)

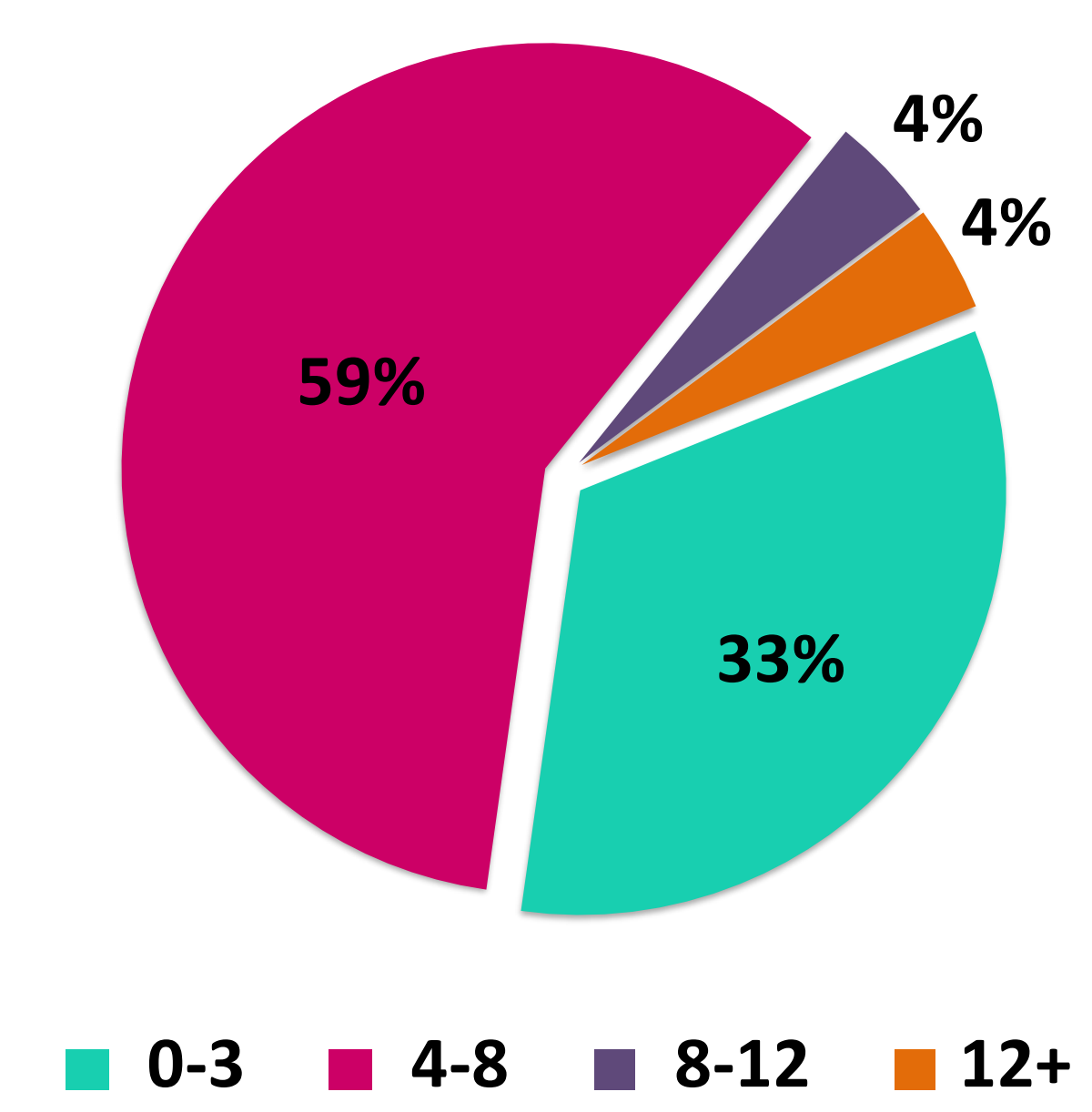

Fig d.

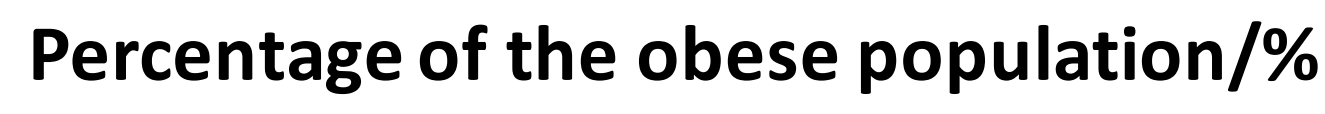

\section{Conclusion}

The data concludes that there is a higher prevalence for some risk factors than others, generally environmental factors show the highest frequency. The aetiology of cataracts can be easily remembered by the 5 Ds (Diabetes, Diet, Drugs, Dehydration and Don't know). Qatar's focus should be driven towards educating the public about the 5Ds and on ways in which positive lifestyle changes can be implemented, so that there's a decrease in the risk of potentially developing a cataract.

$33 \%$ of all survey takers consume the daily requirement

\section{Results} of vitamin C

- Environmental factors contribute about $65 \%$ to the risk of developing cataract. ${ }^{[5]}$

- $5 \%$ of survey takers in the 40-50 age demographic, responded positively to questions in the survey regarding certain symptoms of cataract ex. being bothered by headlight glare. $55 \%$ of people in this category did not have a college education.

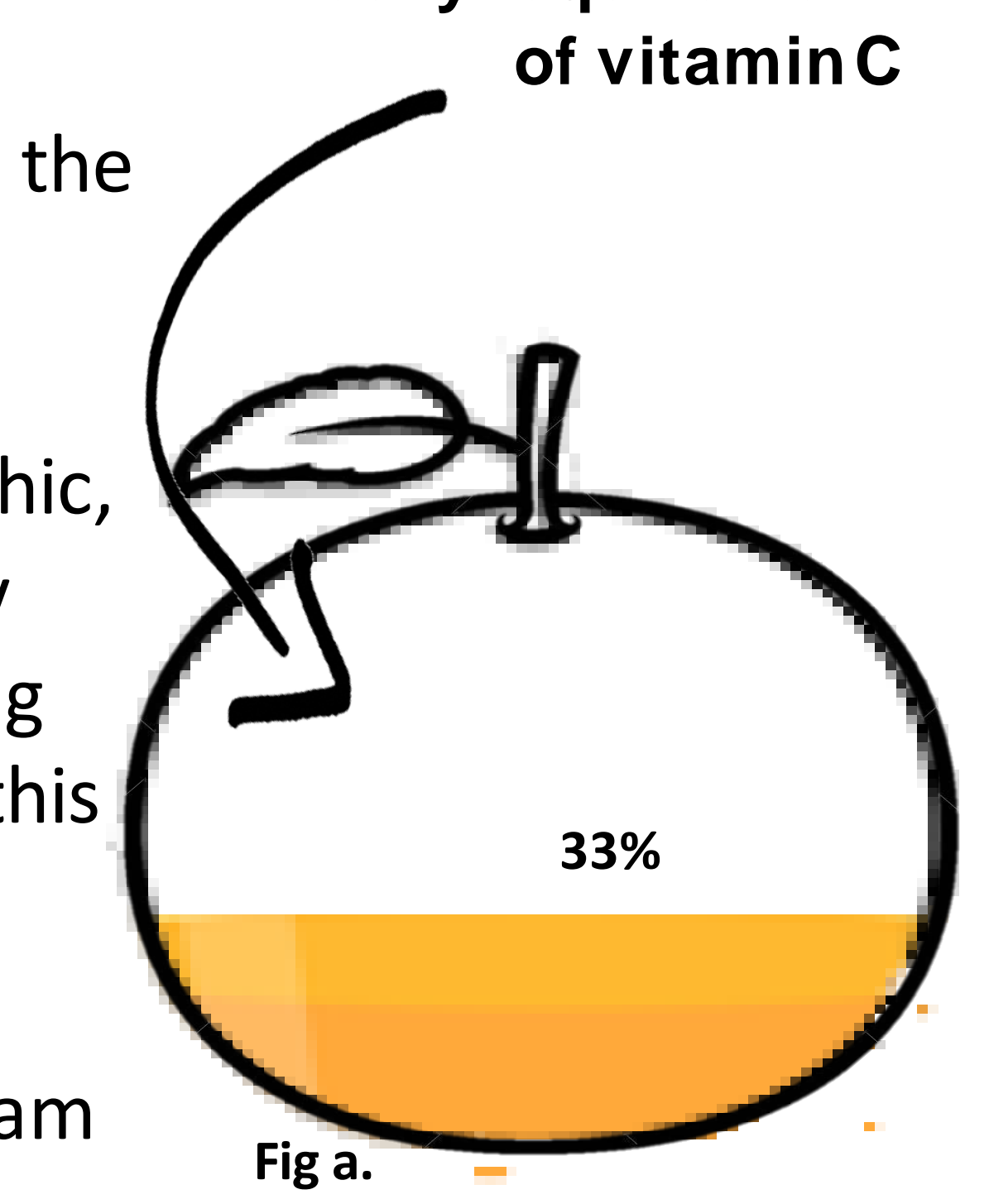

\section{Acknowledgements}

We would like to thank our supervisor, Asim Bukhari, for providing us the necessary resources for conducting this investigation. We would also like to thank our mentor, Becky Cramer for guiding us and giving us genuine advice

\section{References}

1. https://www.who.int/blindness/causes/priority/en/index1.htm

3.Leske, M. C., Chylack, L. T., \& Wu, S. Y. (1991). The lens opacities case-control study: risk factors for cataract. Archives of Ophthalmology, 109(2), 244-251.

4.McCarty, C. A., Nanjan, M. B., \& Taylor, H. R. (2000). Attributable risk estimates for cataract to prioritize medical and public health action. Investigative ophthalmology \& visual science, 41(12), 3720-3725. 5. https://www.nature.com/articles/eye1999119.pdf?origin=ppub

- The average Qatari citizen undergoes an eye exam 6.Yonova-Doing, Ekaterina, et a every 3.2 years. 